\title{
PENENTUAN STRUKTUR SENYAWA ANTIOKSIDAN LIMONOID DARI BIJI JERUK SAMBAL (Citrus microcarpa Bunge) KALIMANTAN BARAT
}

\author{
Setyo Widayanti*, Rudiyansyah, Andi Hairil Alimuddin \\ Program Studi Pascasarjana Kimia, Fakultas MIPA, Universitas Tanjungpura \\ , Jl. Prof. Dr. H. Hadari Nawawi, Pontianak, 74014, Indonesia \\ "Corresponding author: setyowidayanti74@gmail.com
}

\begin{tabular}{l}
\hline ARTICLE INFO \\
Article history: \\
Received 03 \\
November 2018 \\
Accepted 30 \\
November 2018 \\
Available online \\
30 December 2018 \\
Keywords: \\
Antioksidan,Citrus \\
microcarpa Bunge, \\
Limonin, Triterpenoid
\end{tabular}

\begin{abstract}
Limonoid has been isolated from orange seeds of Citrus microcarpa Bunge using extraction and partitioning methods. It is a yellowishwhite crystal with a melting point of $276-277{ }^{\circ} \mathrm{C}$. Based on the phytochemical analysis and FTIR spectroscopy, ${ }^{1} \mathrm{H}$ NMR and compared with the literature, the compound is limonin which is a triterpenoid. The purpose of this study was to determine the structure and evaluate antioxidant activity of the limonin. The antioxidant activity by DPPH obtained IC50 value of limonin was $199.18 \mathrm{ppm}$. Whereas, the test antioxidant activity by FRAP method using a comparative solution of ascorbic acid showed that there was an increasingly blue color change, which meant that antioxidant activity was stronger with activity value of $11.88 \mathrm{mgAAE} / \mathrm{g}$ sample.
\end{abstract}

(C) 2018 IJoPAC. All rights reserved

\section{Pendahuluan}

Jeruk termasuk tumbuhan yang dimanfaatkan sebagai obat tradisional seperti penurun panas, pereda nyeri saluran napas bagian atas, dan penyembuh radang mata ${ }^{[2]}$. Studi farmakologi sebelumnya mengungkapkan bahwa jeruk memiliki aktivitas antimikroba, anthelmintik, anti nyamuk, antioksidan, antikanker, kardiovaskular, saraf pusat, antiinflamasi, analgesik, antidiabetes, gastrointestinal, imunologis, dan pernafasan ${ }^{[3]}$. Salah satu jenis jeruk yang tumbuh di wilayah Kalimantan Barat yaitu jeruk sambal yang berasal dari spesies Citrus microcarpa Bunge.

Berdasarkan beberapa penelitian, tanaman jeruk mengandung berbagai jenis metabolit sekunder. Sikander (2016) melaporkan pada kulit buah C. karna terkandung senyawa metabolit sekunder alkaloid, fenol, tanin, flavonoid, steroid, asam amino, terpenoid, dan saponin ${ }^{[1]}$. Bui et al (2004) telah melakukan isolasi senyawa limonin dari Vietnamese Citrus nobilis ${ }^{[11]}$. Chu et al (2012) telah melakukan isolasi senyawa limonin dari Citrus medica L. Var. sarcodactylis ${ }^{[12]}$. Hasegawa et al (1980) telah melakukan isolasi limonin dari grafefruit ${ }^{[13]}$. (Malee (2011) mengidentifikasi senyawa metabolit sekunder pada daun dan batang $C$. aurantifolia diperoleh enam kelompok senyawa metabolit sekunder: (1) senyawa kumarin, (2) derivat benzene; (3) senyawa flavon; (4) senyawa acridone alkaloid; (5) senyawa limonoid: limonin dan limonexic 
acid, dan; (6) senyawa lignin ${ }^{[4]}$. Kranthi K., et al (2006) sudah melakukan isolasi senyawa limonin dari biji jeruk Red Mexican Grapefruit ${ }^{[5]}$. Can, et al (2012) telah melakukan isolasi senyawa limonin dari Citrus reticulate Blanco ${ }^{[6]}$; Bauri, dkk (2016) telah melakukan isolasi senyawa limonin dari Citrus limetta (Indian sweet lemon) ${ }^{[7]}$; Anshori, dkk (2006) telah melakukan isolasi senyawa limonin pada Citrus nobilis var. Microcarpa (Jeruk Siam) ${ }^{[8]}$.

Hasil penelitian Fajarwati (2014) diketahui bahwa daun jeruk nipis memiliki aktivitas antioksidan yang kuat dengan nilai konsentrasi penghambatan (IC50) 76,90 ppm ${ }^{\text {[9] }}$. Wulandari, dkk (2013) melaporkan bahwa kulit buah jeruk sambal memiliki aktivitas antioksidan baik yang ditunjukkan oleh nilai konsntrasi efektif $\left(\mathrm{EC}_{50}\right)$ untuk ekstrak metanol sebesar 94,01 $\mathrm{g} / \mathrm{mL}$ (antioksidan kategori kuat) ${ }^{[10]}$.

Berdasarkan studi dan uji pendahuluan yang dilakukan oleh peneliti (bulan April-Juli 2018), diketahui bahwa biji jeruk sambal (Citrus microcarpa Bunge) mengandung senyawa golongan triterpenoid dan belum ditemukan laporan tentang struktur senyawa antioksidan golongan triterpenoid pada biji jeruk sambal Kalimantan Barat. Penelitian ini untuk mengetahui struktur kimia dan aktivitas antioksidan senyawa golongan triterpenoid pada ekstrak biji jeruk sambal.

\section{Bahan dan Metode}

\subsection{Pengumpulan Sampel, Alat dan Bahan}

Biji jeruk sambal (Citrus microcarpa Bunge) dikumpulkan dari daerah Radak, Kabupaten Kuburaya, bulan November 2017. Sebanyak $10 \mathrm{~kg}$ biji jeruk sambal basah dibersihkan, kemudian dikeringkan dalam oven suhu $40{ }^{\circ} \mathrm{C}$ sehingga diperoleh $2 \mathrm{~kg}$ biji jeruk sambal kering, setelah itu diblender hingga menjadi serbuk.

Alat yang digunakan pada penelitian ini adalah alat ekstraksi, blender Panasonik, oven Memmert, neraca analitik OHAUS, Lampu UV $\lambda=254 \mathrm{~nm}$ dan $366 \mathrm{~nm}$, Spektrofotometer UVVis merek Genesys 10S buatan Cina, FTIR Prestige 21 Shimadzu Jepang, Nuclear Magnetic Resonance (NMR) Agilent $500 \mathrm{MHz}$ dengan sistem konsol DD2, Rotary evaporator Heidolph dan Melting Point merek Stuart Scientific UK.

Bahan yang digunakan, biji jeruk sambal, metanol p.a, $n$-heksana p.a, kloroform p.a, etilasetat p.a, pereaksi uji fitokimia (asam sulfat, asam asetat), plat silika gel $60 \mathrm{~F}_{254}$, vitamin $\mathrm{C}$ murni, DPPH, dapar fosfat, oksalat, ferrisianida, $\mathrm{FeCl}_{3}$, dan TCA.

\subsection{Ekstraksi dan Partisi}

Sebanyak $2 \mathrm{~kg}$ serbuk biji jeruk sambal kering direndam dalam metanol, lalu diaduk dan dibiarkan selama 3x24 jam. Ekstrak yang diperoleh kemudian disaring dan filtrat dikumpulkan menjadi satu. Filtrat hasil maserasi dievaporasi sampai pekat.

Ekstrak pekat yang diperoleh selanjutnya dipartisi dengan menggunakan pelarut $n$-heksana, etil asetat, dan kloroform. Sebanyak 4 fraksi diperoleh yaitu fraksi $n$-heksana, fraksi kloroform, fraksi etil asetat, dan metanol. Evaporasi kemudian dilakukan pada masing-masing fraksi untuk memperoleh ekstrak pekat. Kristal yang diperoleh dari fraksi pekat $n$-heksana dilakukan uji fitokimia triterpenoid. 


\subsection{Isolasi Senyawa Golongan Triterpenoid}

Kristal yang terbentuk pada fraksi $n$-heksana setelah proses evaporasi dan pendinginan, selanjutnya disaring dan dicuci dengan sejumlah pelarut sampai bersih (kristal menjadi putih kekuningan). Kristal yang diperoleh dikering-anginkan, ditimbang dan dilakukan uji kemurnian yaitu uji KLT dan uji titik leleh.

Isolat murni yang diperoleh dilakukan pengukuran FTIR, ${ }^{1} H$ NMR, dan Isolat selanjutnya dilakukan uji aktivitas antioksidan dengan metode DPPH dan FRAP. Pada metode DPPH, tahapan pengujian antioksidan meliputi pembuatan larutan DPPH, pembuatan larutan kontrol, pembuatan larutan uji (larutan induk 100 ppm dan larutan seri 1 ppm, 2 ppm, 3 ppm, dan 4 ppm), dan pembuatan kontrol positif larutan vitamin $C 1$ ppm, 2 ppm, 3 ppm, dan 4 ppm. Absorbansi metode DPPH selanjutnya diukur menggunakan spektrofotometer UV-Vis pada panjang gelombang $515 \mathrm{~nm}$. Nilai absorbansi yang didapat dan dihitung persen hambatan masing-masing larutan dengan menggunakan rumus:

$$
\% \text { Hambatan }=\frac{A b s_{0}-A b s_{\text {sampel }}}{A b s_{0}} \times 100 \%
$$

Nilai IC50 dicari setelah didapatkan \% aktivitas hambatan melalui persamaan regresi linier $\mathrm{y}=\mathrm{a}+\mathrm{bx}$. Uji aktivitas antioksidan dengan metode FRAP dilihat perubahan warna yang terjadi dan nilai FRAP dinyatakan dalam mg equivalen asam askorbat/gr isolat. Tahapan proses yang dilakukan yaitu sebanyak $5 \mathrm{mg}$ sampel dilarutkan dalam $5 \mathrm{~mL}$ etil asetat, lalu dipipet $1 \mathrm{~mL}$, ditambahkan $1 \mathrm{~mL}$ dapar fosfat $0,2 \mathrm{M}\left(\mathrm{pH}\right.$ 6.6) dan $1 \mathrm{~mL} \mathrm{~K} \mathrm{~K}_{3} \mathrm{Fe}(\mathrm{CN})_{6} 1 \%$ setelah itu, diinkubasi selama 20 menit dengan suhu $50^{\circ} \mathrm{C}, 1 \mathrm{~mL}$ TCA ditambahkan, dipipet $1 \mathrm{~mL}$ ke dalam tabung reaksi, dan ditambahkan $1 \mathrm{~mL}$ aquades dan $0,5 \mathrm{~mL} \mathrm{FeCl}$ 0,1\%. Larutan didiamkan selama 10 menit dan diukur absorbansinya pada $720 \mathrm{~nm}$. Sebagai blangko digunakan campuran larutan oksalat. Kurva kalibrasi dibuat menggunakan larutan asam askorbat dengan berbagai konsentrasi. Nilai FRAP dinyatakan dalam mg equivalen asam askorbat/g sampel

\section{Hasil dan Pembahasan}

Hasil partisi dan evaporasi dari fraksi $n$-heksan diperoleh ekstrak pekat, 14,22 gram dari ektrak pekat tersebut dihasilkan kristal putih kekuningan sebanyak 2,93 gram dengan titik leleh 276-277 ${ }^{\circ} \mathrm{C}$. Senyawa dikatakan murni karna memiliki titik leleh dengan rentang $\pm 2{ }^{\circ} \mathrm{C}$ Interpretasi spektrum IR (KBr) menunjukan adanya ulur $\mathrm{C}-\mathrm{H}$ metil $\left(2966,52 \mathrm{~cm}^{-1}\right)$, ulur $\mathrm{C}-\mathrm{H}$ metilen $\left(2931,80 \mathrm{~cm}^{-1}\right)$, ulur $\mathrm{C}=\mathrm{O}$ ester $\left(1757,15 \mathrm{~cm}^{-1}\right)$, ulur $\mathrm{C}=\mathrm{O}$ alifatik keton, tekuk $\mathrm{C}-\mathrm{H}$ metil metilen $\left(1462,04 \mathrm{~cm}^{-1}\right)$, tekuk $\mathrm{C}$-H metil $\left(1363,67 \mathrm{~cm}^{-1}\right)$, tekuk $\mathrm{C}-\mathrm{O}-\mathrm{C}$ eter $\left(1026,13 \mathrm{~cm}^{-1}\right)$.

Interpretasi spektrum ${ }^{1} \mathrm{H}$ NMR menunjukkan adanya 4 sinyal proton singlet kelompok metil yaitu pada $\delta_{\mathrm{H}} 1,07, \delta_{\mathrm{H}} 1,17, \delta_{\mathrm{H}} 1,25$, dan $\delta_{\mathrm{H}} 1,29, \alpha$-proton furan ${ }^{[8]}\left[\delta_{\mathrm{H}} 7,41(1 \mathrm{H}, d\right.$, $\left.J=5,65 \mathrm{~Hz}), \delta_{\mathrm{H}} 7,40(1 \mathrm{H}, s)\right], \beta$-proton furan ${ }^{[8]}\left[\delta_{\mathrm{H}} 6,34(1 \mathrm{H}, s)\right]$, empat proton gugus metoksi $\left[\delta_{\mathrm{H}}\right.$ $5,47(1 \mathrm{H}, s), \delta_{\mathrm{H}} 4,04(1 \mathrm{H}, s), \delta_{\mathrm{H}} 4,46(2 \mathrm{H}, d, J=13,10 \mathrm{~Hz})$, dan $\left.\delta_{\mathrm{H}} 4,08(1 \mathrm{H}, s)\right]$. Spektrum dari senyawa isolat Citrus microcarpa Bunge dibandingkan dengan isolat Citrus aurantifolia Swingle karena Genusnya sama dan menggunakan pelarut yang sama $\left(\mathrm{CDCl}_{3}\right)$ dengan titik leleh 285-286 ${ }^{\circ} \mathrm{C}$ Berikut perbandingan spektrum ${ }^{1} \mathrm{H}$ NMR dengan konsol DD2 $500 \mathrm{MHz}$ pada Citrus microcarpa Bunge dan Citrus aurantifolia Swingle: 
Tabel 1 menunjukkan bahwa spektrum ${ }^{1} H$ NMR C. microcarpa dibandingkan dengan spektrum ${ }^{1} H$ NMR $C$. aurantifolia Swingle mempunyai kemiripan pergeseran $\mathrm{H}^{[4]}$. Hal tersebut dapat diprediksi bahwa kristal dari fraksi $n$-heksana biji jeruk sambal (Citrus microcarpa Bunge) adalah suatu senyawa golongan limonoid yaitu limonin dengan struktur berikut ini:

Tabel 1 Perbandingan Spektrum ${ }^{1} H$ NMR Citrus microcarpa Bunge dan Citrus aurantifolia Swingle

\begin{tabular}{|c|c|c|c|}
\hline Posisi & $\begin{array}{l}\text { Pergeseran H (Multiplet) } \\
\text { (Citrus microcarpa Bunge) }\end{array}$ & $\begin{array}{c}\text { Pergeseran H (Multiplet) } \\
\text { (Citrus aurantifolia }^{(4)} \text { Swingle) }^{(4)}\end{array}$ & Tipe \\
\hline $\mathbf{1}$ & $4,04(s)$ & $4,09(b r s)$ & $\mathrm{CH}$ \\
\hline \multirow[t]{2}{*}{2} & $2,31(d d, J=15.4,3.4)$ & $2,30(d d, J=15.0,3.0)$ & \multirow{2}{*}{$\mathrm{CH}_{2}$} \\
\hline & $2,67(d d, J=16.75,3,4)$ & $2,70(d d, J=15.0,3.0)$ & \\
\hline 3 & - & - & - \\
\hline 4 & - & - & - \\
\hline 5 & $2,46(d d, J=17.9,3,4)$ & $2,44(d d, J=12.0,3.0)$ & $\mathrm{CH}$ \\
\hline \multirow[t]{2}{*}{6} & \multirow[t]{2}{*}{$2,93(d d, J=16.8,3,4)$} & $2,73(d d, J=12.0,3.0)$ & \multirow{2}{*}{$\mathrm{CH}_{2}$} \\
\hline & & $3,16(d d, J=12.0,3.0)$ & \\
\hline 7 & - & - & - \\
\hline 8 & - & - & - \\
\hline 9 & $2,54(d d, J=9.5,2.9)$ & $2,58(d d, J=9.0,3.0)$ & $\mathrm{CH}$ \\
\hline 10 & - & - & - \\
\hline \multirow[t]{2}{*}{11} & $1,80(m)$ & $1,87(m)$ & \multirow[b]{2}{*}{$\mathrm{CH}_{2}$} \\
\hline & $1,79(m)$ & $1,78(m)$ & \\
\hline \multirow[t]{2}{*}{12} & $1,51(m)$ & $1,51(m)$ & \multirow{2}{*}{$\mathrm{CH}_{2}$} \\
\hline & $1,89(m)$ & $1,82(m)$ & \\
\hline 13 & - & - & - \\
\hline 14 & - & - & - \\
\hline 15 & $4,03(s)$ & $4,05(s)$ & $\mathrm{CH}$ \\
\hline 16 & - & - & - \\
\hline 17 & $5,47(s)$ & $5,48(s)$ & $\mathrm{CH}$ \\
\hline 18 & $1,17(s)$ & $1,17(s)$ & $\mathrm{CH}_{3}$ \\
\hline \multirow[t]{2}{*}{19} & $4,46(d, J=13,1)$ & $4,50(d, J=12.0)$ & \multirow{2}{*}{$\mathrm{CH}_{2}$} \\
\hline & $4,76(d, J=13,05)$ & $4,82(d, J=12.0)$ & \\
\hline 20 & - & - & - \\
\hline 21 & $7,40(s)$ & $7,42(s)$ & $\mathrm{CH}$ \\
\hline 22 & $6,34(s)$ & $6,36(d, J=1.5)$ & $\mathrm{CH}$ \\
\hline 23 & $7,41(d, J=5,65)$ & $7,45(d, J=1.5)$ & $\mathrm{CH}$ \\
\hline 24 & $1,07(s)$ & $1,08(s)$ & $\mathrm{CH}_{3}$ \\
\hline 25 & $1,25(s)$ & $1,25(s)$ & $\mathrm{CH}_{3}$ \\
\hline 26 & $1,29(s)$ & $1,16(s)$ & $\mathrm{CH}_{3}$ \\
\hline
\end{tabular}




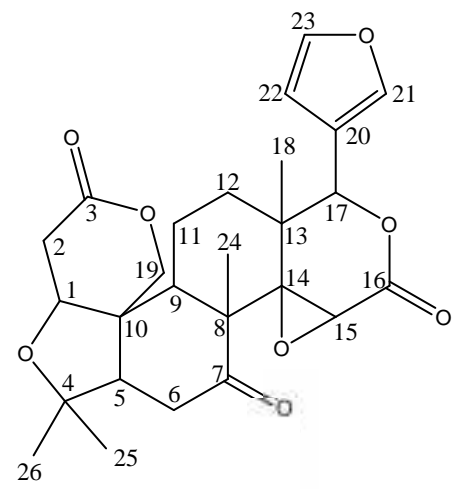

Gambar 1 Prediksi Struktur dari Data Spektrum ${ }^{1} H$ NMR dan FTIR C. microcarpa Bunge

Kristal yang diperoleh dari fraksi $n$-heksana selanjutnya dilakukan uji antioksidan menggunakan metode DPPH dan FRAP. Hasil Uji DPPH menunjukkan nilai $\mathrm{IC}_{50}$ senyawa limonin dari biji jeruk sambal sebesar 199,18 ppm yang merupakan antioksidan lemah menurut klasifikasi Blois.

Tabel 2. Klasifikasi Aktivitas Antioksidan

\begin{tabular}{ccc}
\hline No. & Nilai I $\mathbf{C}_{\mathbf{5 0}}$ & Antioksidan \\
\hline 1. & $<50 \mathrm{ppm}$ & Sangat kuat \\
2. & $50-100 \mathrm{ppm}$ & Kuat \\
3. & $100-150 \mathrm{ppm}$ & Sedang \\
4. & $151-200 \mathrm{ppm}$ & Lemah \\
\hline
\end{tabular}

Sedangkan hasil uji aktivitas antioksidan metode FRAP dengan pengulangan tiga kali dan konsentrasi sampel yang sama menunjukkan aktivitas antioksidan yang terkandung dalam biji jeruk sambal sebesar 11,88 mgAAE/g sampel. Aktivitas antioksidan semakin kuat ditandai dengan makin pekatnya warna biru yang terbentuk pada sampel ${ }^{[14]}$.

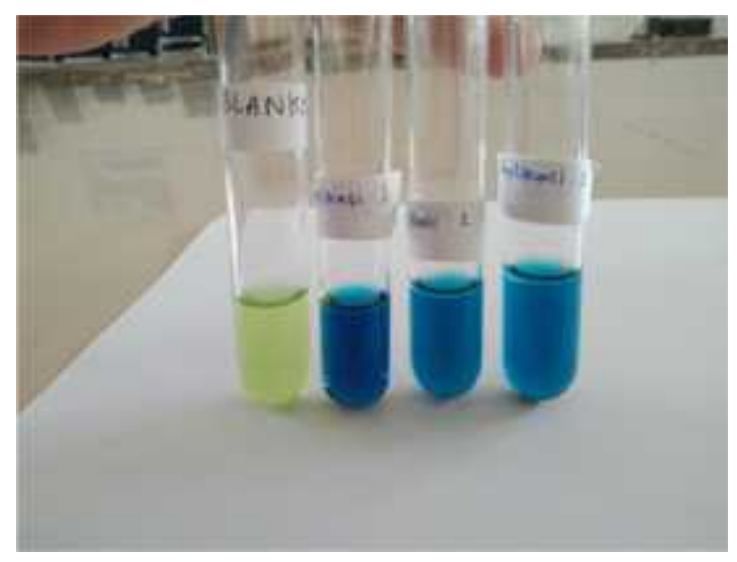

Gambar 2 Hasil Uji Kualitatif Aktivitas Senyawa Limonin Metode FRAP

\section{Kesimpulan}

Berdasarkan penelitian yang telah dilakukan, dapat disimpulkan hasil partisi dan rekristalisasi yang diperoleh berbentuk kristal berwarna putih kekuningan dengan hasil uji fitokimia menunjukkan adanya senyawa golongan triterpenoid. Berdasarkan data spektrum ${ }^{1} H$ NMR dan FTIR diprediksi golongan triterpenoid yang terkandung di dalam kristal fraksi $n$-heksana adalah senyawa limonin. Uji aktivitas antioksidan yang telah dilakukan terhadap kristal fraksi $n$-heksana dengan metode DPPH diperoleh nilai IC 50 sebesar 199,18 ppm dan uji antioksidan menggunakan 
metode FRAP menunjukkan adanya perubahan warna semakin biru berarti aktivitas antioksidan semakin kuat dengan nilai aktivitas antioksidan sebesar 11,88 mgAAE/g sampel.

\section{DAFTAR PUSTAKA}

[1] Sikander, Dar M. (2016). Study of Phytoconstituents, antioxidant and Antibacterial Activities of Citrus karna Fruits Peels. Thesis. Technology and Sciences, Allahabad: India.

[2] Kemenristekdikti. (2017). Jeruk. http://migroplus.com/brosur/Budidaya\%20 jeruk.pdf, diakses tanggal 02 Februari 2017.

[3] Al-Snafi, A. Esmail. (2016). Nutritional value and pharmacological importance of citrus species grown in Iraq. Journal of Pharmacy, 6(8), 76-108.

[4] Malee, Tareeyah. (2011). Chemical Constituents from the Leaves and Stems of Citrus aurantifolia Swingle. Thesis. Master of Science Degree. Prince of Songkla University: Songkla.

[5] Kranthi K. Mandadia,b, Guddadarangavvanahally K. Jayaprakashaa,b, Narayan G. Bhatc, dan Bhimanagouda S. Patila. (2006). Red Mexican Grapefruit: A Novel Source for Bioactive Limonoids and their Antioxidant Activity. Vegetable and Fruit Improvement Center, 62c, 179188.

[6] Can Liu, Jing Liu, Yonghai Rong, Nvyong Liang dan Long Rong. (2012). Aqueous extraction of limonin from Citrus reticulate Blanco. Czech J. Food Sci, 4(30), 364-368.

[7] Bauri, A. K., Sabine Foro dan Quynh Nguyen Do Nhu. (2016). Limonin isolated from the seeds of Citrus limetta (Indian sweet lemon). IUCrData, 1, x160172.

[8] Anshori, J., Al, Euis Julaeha, Tri Mayanti, Unang Supratman, Hideo Hayashi. (2006). Senyawa Limonin dari Biji Jeruk Citrus nobilis var. Microcarpa (Jeruk Siam) dan Potensi Aktivitasnya sebagai Penghambat Tumbuh Larva Instar ke-empat Nyamuk Aedes Aegypti, Jurnal Riset dan Teknologi Pembangunan Perekonomian.

[9] Fajarwati, N. (2013). Uji Aktivitas Antioksidan Pada Ekstrak Daun Jeruk Nipis (Citrus aurantifolia) Dengan Menggunakan Metode DPPH (1,1-DIPHENYL-2-PICRYLHYDRAZYL). Skripsi. FKIK. UIN Syarif Hidayatullah: Jakarta.

[10] Wulandari, M., Nora Idiawati, Gusrizal. (2013). Aktivitas Antioksidan Ekstrak n-Heksana, Etil Asetat dan Metanol Kulit Buah Jeruk Sambal (Citrus microcarpa Bunge). JKK. 2(2), 94-94.

[11] Bui, K. A., Duong, A. T., Tran, V. S., Seip, S. (2004). Isolation and structure elucidation of a new limonoid from Vietnamese Citrus nobilis seeds. Tap. Chi. Hoa. Hoc., 42(4), 520-523.

[12] Chu, J., Song-Lin Li, Zhi-Qi Yin, Wen-Cai Ye, Qin-Wen Zhang. (2012). Simultaneous Quantification of Coumarins, Flavonoids, and Limonoids in Fructus Citri Sarcodactylis by High Performance Liquid Chromagraphy Coupled With Diode Array Detector. Journal of Pharmaceutical and Biomedical analysis. 66, 170-175.

[13] Hasegawa, S., raymond D. Bennett, dan Carl P. Verdon. (1980). Metabolism of Limonoids Via a Deoxylimonoid Pathway in Citrus. Phytochemistry. (19), 1445-1447.

[14] Huang D., Boxin Ou, dan Ronald L. Prior. (2005). The Chemistry behind Antioxidant Capacity Assays. Journal Agric. Food Chem., 6(53), 1841-1856. 